\title{
Modeling and Simulation of Battery Management System (BMS) for Electric Vehicles
}

\author{
Ravi P Bhovi ${ }^{1}$, Ranjith A C ${ }^{2}$, Sachin $\mathrm{K} \mathrm{M}^{3}$ and Kariyappa B S ${ }^{4}$. \\ ${ }^{1}$ Dept of Electronics and Communication, RV College of Engineering, India, \\ ${ }^{2}$ Dept of Electronics and Communication, RV College of Engineering, India, \\ ${ }^{3}$ Dept of Electronics and Communication, RV College of Engineering, India \\ ${ }^{3}$ Dept of Electronics and Communication, RV College of Engineering, India \\ ${ }^{1}$ ravibhovi.ec14@rvce.edu.in, ${ }^{2}$ ranjithac.ec17@ rvce.edu.in, ${ }^{3}$ sachinkm.ec17@ rvce.edu.in and \\ ${ }^{3}$ kariyappabs@rvce.edu.in
}

\begin{abstract}
Electric cars have evolved into a game-changing technology in recent years. A Battery Management System (BMS) is the most significant aspect of an Electric Vehicle (EV) in the automotive sector since it is regarded the brain of the battery pack. Lithium-ion batteries have a large capacity for energy storage. The BMS is in charge of controlling the battery packs in electric vehicles. The major role of the BMS is to accurately monitor the battery's status, which assures dependable operation and prolongs battery performance. The BMS' principal job is to keep track, estimate, and balance the battery pack's cells. The major goals of this work is to keep track of battery characteristics, estimate SoC using three distinct approaches, and balance cells. Coulomb Counting, Extended Kalman Filter, and Unscented Kalman Filter are the three algorithms that will be implemented. Current is used as an input parameter to implement the coulomb counting method. In contrast to voltage and temperature, the current value is taken into account by the Extended and Unscented Kalman Filters. To calculate the state transition and measurement update matrix, these parameters are considered. This matrix will then be used to calculate SoC. Results of all the algorithms will be comparatively analyzed.

MATLAB R2020a software is used for the simulation of different algorithms and SoC calculation. Three states of BMS are considered and they are Discharging phase, the Standby/resting phase, and the Charging phase. At the beginning of the Simulation, the SoC values of the cells were 80\%. At the end of simulation maximum values of SoC of Coulomb counting, Extended Kalman Filter (EKF), and Unscented Kalman Filter $(U K F)$ reached are $100 \%, 98.74 \%$ and $98.46 \%$ respectively. After SoC Estimation, Cell balancing is also performed over 6 cells of the battery pack.
\end{abstract}

Keywords: Electric Vehicle (EV), State-of-Charge (SOC), Unscented Kalman Filter (UKF), Extended Kalman Filter (EKF), Battery Pack Current, Coulomb Counting (CC), State-of-Health (SOH), Battery Management System (BMS), Cell balancing.

\section{Introduction}

The electrifying of transportation systems and the need to make electric products portable are driving up global usage of electric batteries, that will account for the great majority of battery needs in terms of total power storage. With the increasing demand for batteries, the level of quality must be sustained. Several factors influence battery performance, including ambient temperature, charging, and battery composition. The state of charge (SoC) of a battery is acknowledged as a critical metric. Its correct estimation can lengthen the battery's life cycle, improve battery performance, and improve the system's safety and dependability. It's indeed, however, impossible to estimate SoC directly. The fundamental issue is that direct calculations are erroneous due to the console's nonlinearity, temperature, and time-dependent properties of the battery. Different techniques have been created to quantify SoC, and researchers all around the globe are continually working on new approaches. The state of charge (SoC) and cell balance are critical indications for determining a battery's usefulness and capabilities. The SoC and Cell balancing work together to offer a state of function, a battery overview, and a comprehensive perspective of the pack's capabilities. Along with these indicators, Cell balancing and Charge limit calculation is also important factors in case of battery health and efficient performance. 


\section{Battery Management System}

In electric and hybrid cars, the Battery Management System is crucial to attaining battery performance and extending battery life. Electric vehicles have become more popular as a result of government regulations limiting $\mathrm{CO} 2$ emissions and encouraging emission-free transportation. Electric vehicles' primary drawbacks include restricted driving range, high price, battery difficulties, and inconsistent charging. Lithium- ion batteries were introduced to solve this problem. Battery packs have been embraced for mobile electronic gadgets and electric cars due to high efficient energy densities. They've become more popular in a variety of applications, including small mobility vehicles, trucks/buses, and industrial gear. The inappropriate utilization of battery leads to electric shock and fire. A Battery Management System (BMS) is necessary to use battery packs effectively and safely.

A BMS may be thought of as the brain of a battery pack, monitoring pack current, cell voltage, cell temperatures, and determining available energy throughout the cells, state of charge (SOC), and status of health $(\mathrm{SOH})$ in order to maintain cells within safe operating limits and extend cell life. The increased reliance on battery packs for power storage has highlighted the significance of battery management systems (BMSs) that can assure optimal performance, reliable handling, and long lifespan under a variety of chargedischarge and atmospheric circumstances across sectors. Engineers create feedback and supervisory control algorithms to construct a BMS that meets these goals. Keep an eye on the voltage and temperature of the cells.

The proposed BMS model in this paper has two major components namely BMS Controller and Battery plant. The battery plant has a 6 cells module, pre-charge circuit, charger, and inverter. Along with this, BMS Model is composed of a charge limit block, state machine, SOC estimation block, and cell balancing circuit model. The battery parameters like input and output current for each cell, cell voltages, cell temperatures and pack current values are extracted from the battery module through the appropriate sensors. These parameter values will be given to the controller as inputs. Taking these inputs, the controller calculates the input and output charge limits, provides the SOC information to the user, and also sends the cell balancing command to the battery plant.

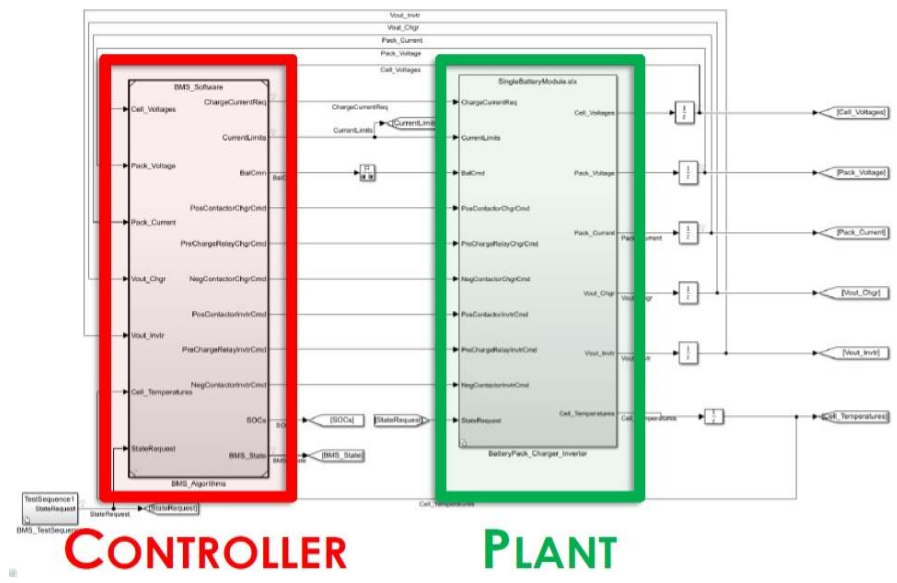

Figure 1. BMS Model overview [3]

The BMS Model overview with inputs and outputs is depicted in Figure 1.

\section{State-Of-Charge Estimation}

The proportion of charge existing inside a rechargeable battery is known as the State-of-Charge (SoC). The discharge rate and temperature have an impact on the State of Charge. The SOC is a percentage assessment of the amount of available charge in a battery at a given moment in time and expressed it in \%. The SOC tells the user how long the battery may last before it has to be charged or updated. Battery parameters such as temperature and voltage may be directly monitored using proper instruments. Because of its non-linearity, SOC cannot be calculated directly and must be estimated. Because there is no appropriate sensor to measure the state of charge, it is difficult to calculate. SOC is a state parameter that varies dynamically throughout time. As a result, a variety of mathematical and analytical methods have been developed and are being used. As a result, a variety of mathematical and analytical meth- ods have been developed and are being used. The charge of a battery degrades when the active material on the elec- trodes wears away. Coulomb Counting, Unscented Kalman Filter(UKF), and Extended Kalman Filter(EKF) are the sug- gested SOC estimation methods in this study. 


\section{A. Coulomb Counting Method}

Ampere-hour counting and current integration are other names for this procedure. This is also the most frequent method for calculating the SoC. To determine SoC values, it uses battery current data that have been mathematically integrated over time. The remaining capacity is then calculated using the coulomb counting method, which accumulates the charge moved in and out of the battery. The accuracy of this approach is mostly determined on a precise measurement of the battery current and a precise estimate of the initial SoC. The State-of-Charge of a battery may be computed by integrating the charging and discharging currents during the working periods with a known capability, which may be originally determined by the operating parameters. During the charging and discharging processes, heat is lost. In addition to self-discharging, these losses result in accumulated mistakes. These aspects should be considered for a more accurate and exact SoC assessment of the battery. Furthermore, the SoC must be re-calibrated on a regular basis, and the decline of the discharging charge should be taken into account with a more precise estimation. To solve the drawbacks of the coulomb counting approach and increase its estimation accuracy, an upgraded coulomb counting technique has been devised for calculating the SoC. As a result, the SoC estimation becomes more exact and accurate. The proportion of the releasable regarding sustainability to the nominal battery is the state of charge.

\section{B. Extended Kalman Filter}

The Kalman filter is a method for estimating a battery's SoC. It may also be utilised to figure out what a dynamic system's inner states are. Under process and measurement noise, the Kalman filter provides an efficient state estimator for linear systems. The Extended Kalman filter is a nonlinear system's version of the Kalman filter. Extended Kalman filter linearizes functions based on their mean and covariance. There are two phases to the estimating process. The initial step is to update the time in order to estimate the states. This type of estimating is referred to as a priori estimate. The states from the previous iteration, an input signal sample, and the process covariance matrix are used as input signals in this stage. The second stage is to update the measurement, which is done through feedback. This stage is known as a posteriori estimate and is symbolised by the carat symbol. It employs inaccuracy in calculating output signal to correct a priori prediction of the states.

\section{Unscented Kalman Filter}

The Unscented Kalman filter, unlike the EKF, doesn't really linearize state-space equations. Instead, it uses a nonlinear Unscented Transformation (UT), in which the mean and error covariance are computed and updated repeatedly, to produce sigma points for states. All sigma points are then transmitted via nonlinear model functions, providing an a priori approximation of the states and output signal. Depending on their statistics, the mean and covariance of those variables are determined [5].

\section{Cell Balancing}

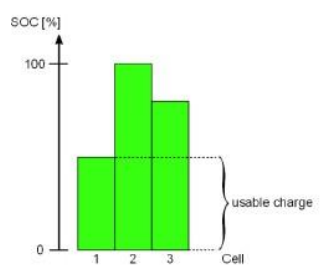

(a) Unbalanced

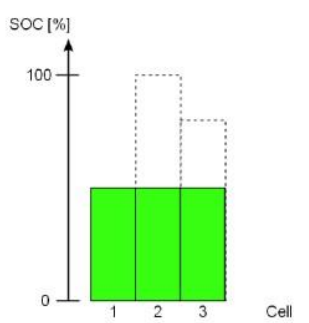

(b) Balanced

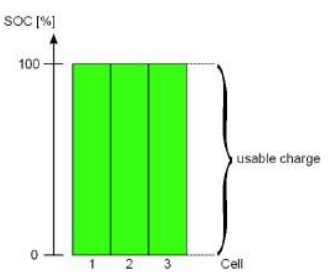

(c) Recharging

Figure 2. Balancing of cells with different states of charge.

Cell balancing is a critical feature of every BMS since it ensures that each cell has the same amount of charge and so maximizes the overall energy available in the pack. The energy of the entire battery pack is restricted by the block with the lowest charge. All blocks require equal amount of charge in order to supply its maximum energy capacity. As shown in figure 2, battery pack capacity is limited to the weakest cell (figure a), A pack for balancing (figure b), after recharging the balanced battery pack, the total capacity available (figure c).

The circuit to illustrate the passive balancing is shown in the Figure 3 Passive balancing approaches work by removing charge from the highest cells until the charge of the lowest cells is equal. This is accomplished by discharging the extra charge through resistors that are switched by transistors in their active state. Methods for passive balancing can be used in two ways. The first method is to use a fixed shunt resistor [7], and the second method is to use a controllable shunt resistor [10]. Although it does not appear to be as elegant 
as active balancing since energy is spent in heat, there are number of reasons why this technique has become the preferred method of most BMS, including: Simple design, low-cost parts, simple installation, and expandable design. Passive balancing [11] can be used with a cooling system to maintain the battery pack temperature under control.

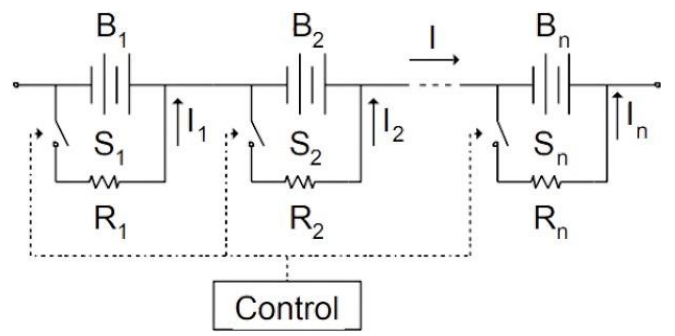

Figure 3. Passive Balancing using resistors to dissipate additional energy

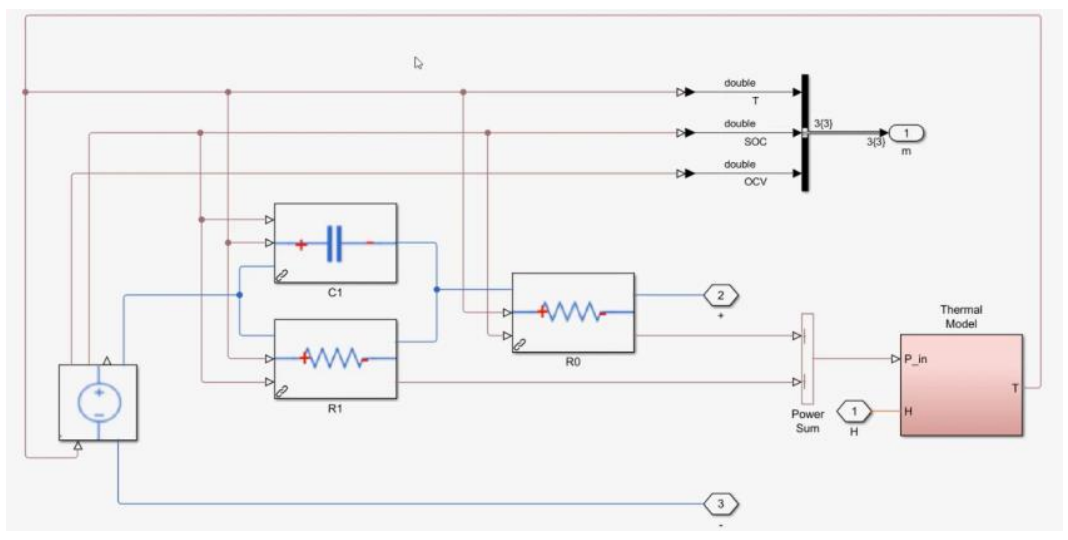

Figure 4. Lithium Cell

\section{Simulation}

In this section, simulation of SOC estimation and cell balancing is discussed. A battery pack of 6 lithium cells is considered for the process. A typical lithium cell configuration is shown in fig 4. Using this cell configuration, the battery parameter like Voltage, Current and temperature of each cell is extracted using appropriate sensors. The 6 cells configuration is shown in fig 5. This model shows a single battery module. A single battery module consists of six individual cells connected in series. The reason for making these modules is to increase the efficiency of the system and to simulate different configurations. It can be observed that each cell is equipped with an individual thermal element that gives out the temperature of the individual cells. Along with the temperature, voltage and current are also noted of each cell. This helps to calculate SoC accurately and reduces the chances for junk value. The State of Charge estimation is done using three meth- ods namely, the Coulomb Counting method, the Unscented Kalman filter \& the Extended Kalman Filter. In Coulomb Counting method current and temperature from the battery plant is given as inputs, whereas Kalman filters accept cell voltages as inputs and predict the SOC values. The CC configuration is shown in fig 6. Coulomb Counting method basically deals with the current owing out of the cells to calculate SoC. This could be illustrated with the expression given in equation 2. The two versions of the Kalman filter are shown in fig 7. Both versions are modeled in Simulink R2020a. Cell voltages. 


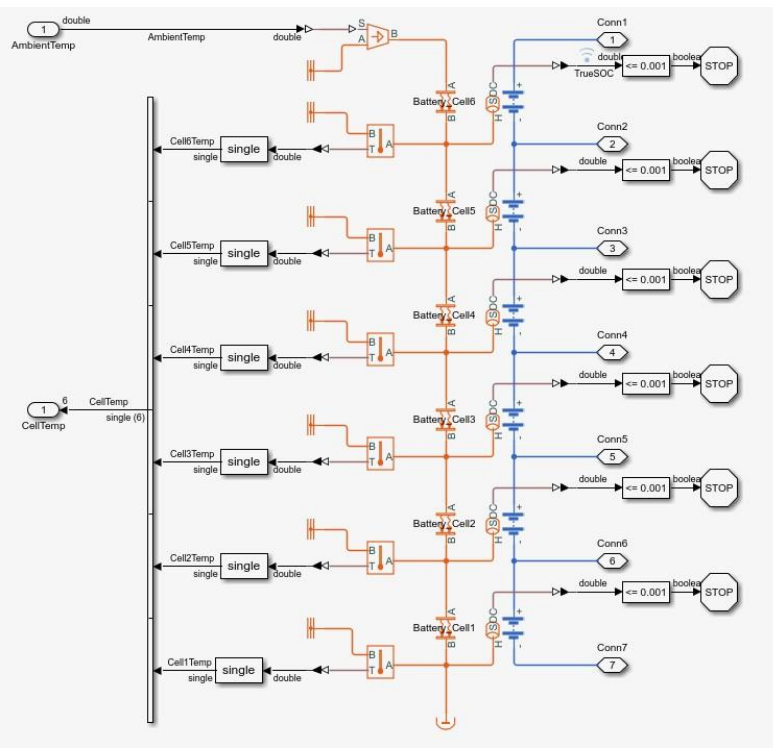

Figure 5. Six cells battery pack

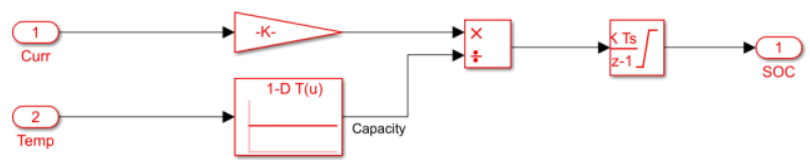

Figure 6. Simulink Model of Coulomb Counting method

are given as input to them. The non-linear Kalman filter versions Extended Kalman Filter and Unscented Kalman Filter rely on the unit cell model to forecast a terminal voltage arising from a current input, thus predicting the internal cell states. Both the methods have two common steps involved in estimating SoC: State update and Measurement update. Both the methods take cell voltage, state transition function, and measurement function as input. Similarly, state transition and measurement function take previous SoC, temperature, and current to evaluate the block result. All the outputs are transferred from the output port to the BMS info port.

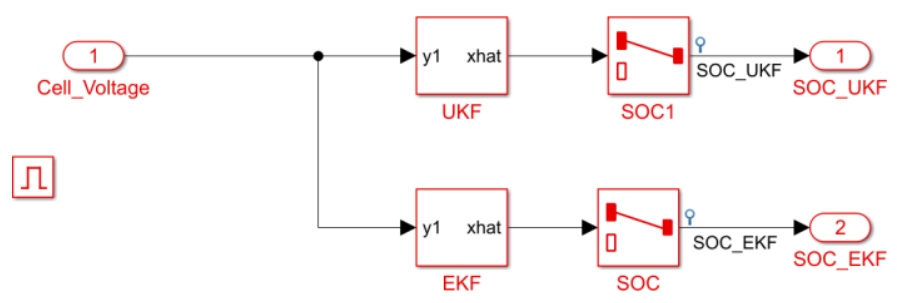

Figure 7. Simulink model of Kalman Filters (UKF \& EKF)

current are shown graphically and the values are tabulated in the following subsections. Also, the comparison of three SOC estimation methods and cell balancing results are discussed. 


\section{Results and Analysis}

After Simulating the BMS model, the battery parameters such as cell voltages, cell temperatures, and battery pack.

\section{A. Cell Voltages}

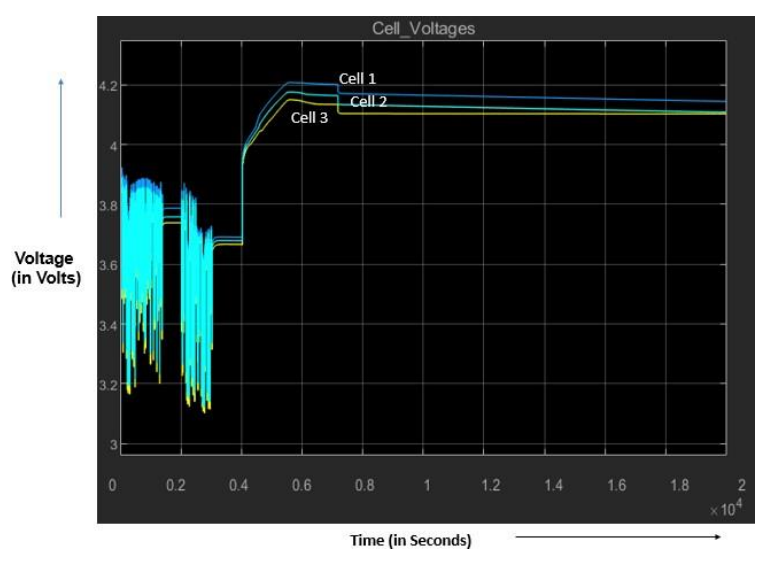

Figure 8. Cell voltages

Figure 8 shows the voltage across each cell of the battery pack will be exactly the same during any mode of operation. The current flowing in and out of the battery causes the cell voltage to fluctuate. Because the model is set up with a slight SoC imbalance and the BMS is in discharge mode, cell voltages are slightly fluctuating at the start of the simulation. As a result of the balancing, the values converge towards one another at the end of the simulation. The Table 1 gives adetailed description of graph.

During Discharging phase the Cell voltage of the battery pack gradually decreased from 3.8V to 3.48V. During Standby Cell voltage is showing 3.6V. When BMS is at the beginning of the Charging phase then the Cell voltage starts increasing.

Table 1. Cell Voltages Based on BMS States

\begin{tabular}{|c|c|c|}
\hline Serial no. & State & $\begin{array}{c}\text { Obtained } \\
\text { Voltage[V] }\end{array}$ \\
\hline 1 & $\begin{array}{l}\text { Beginning of } \\
\text { Discharge }\end{array}$ & 3.8 \\
\hline 2 & $\begin{array}{c}\text { End of } \\
\text { Discharge }\end{array}$ & 3.48 \\
\hline 3 & During Standby & 3.6 \\
\hline 4 & $\begin{array}{c}\text { Beginning of } \\
\text { Charging }\end{array}$ & 4.021 \\
\hline 5 & End of Charging & 4.171 \\
\hline 6 & $\begin{array}{l}\text { Max. Voltage } \\
\text { Value }\end{array}$ & 4.208 \\
\hline
\end{tabular}

\section{B. Cell Temperature}

When the battery is charging or discharging, the temperature generated in the Battery model is roughly proportional to the current through it. The temperature traces reflect a massive variation between the hottest and coldest cells. Figure 9 shows the cell temperatures of the battery pack based on BMS states accordingly. Because it is thermally insulated on one side, cell 1 gets considerably hotter than cell 6 . Active thermal regulation is preferred due to the significant temperature difference between the edge cells. Table 2 gives a detailed description of the graph. 


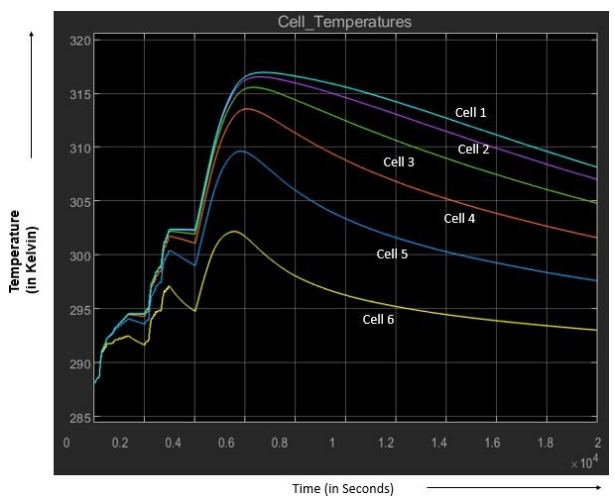

Figure 9. Cell temperatures

Table 2: Cell 1 Temperatures Based on BMS States

\begin{tabular}{|l|l|c|}
\hline Serial no. & State & $\begin{array}{l}\text { Obtained } \\
\text { Temperature[K] }\end{array}$ \\
\hline 1 & $\begin{array}{l}\text { Beginning of } \\
\text { Discharge }\end{array}$ & 288.1 \\
\hline 2 & $\begin{array}{l}\text { End of } \\
\text { Discharge }\end{array}$ & 297.1 \\
\hline 3 & During Standby & 295.7 \\
\hline 4 & $\begin{array}{l}\text { Beginning of } \\
\text { Charging }\end{array}$ & 297.3 \\
\hline 5 & End of Charging & 297.6 \\
\hline 6 & $\begin{array}{l}\text { Max. Temperature } \\
\text { Value }\end{array}$ & 302.8 \\
\hline
\end{tabular}

\section{Pack Current}

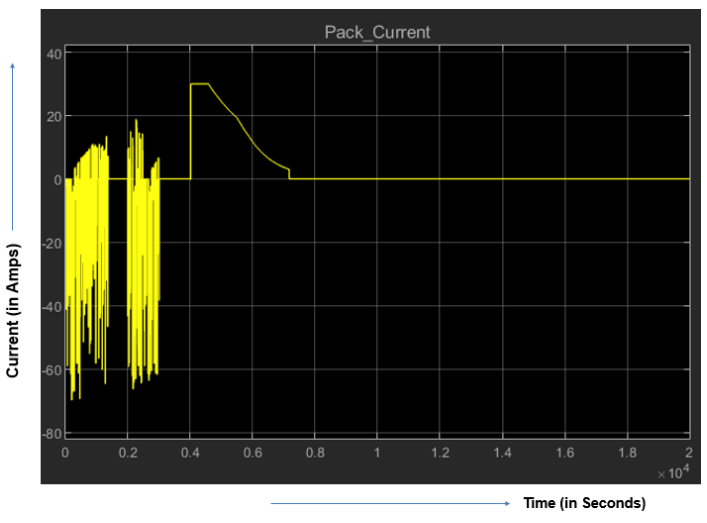

Figure 10. Battery pack current 
Fig 10 shows the variation of cell current in different modes of BMS. The current limit is calculated based on the maximum resistance of the battery cell. Initially, the current fluctuates during the discharge state due to variation of factors across load. During standby state, the graph goes to zero. Then later during the charging state the current increases and reach its peak value as cell voltage reaches its maximum value. With the help of a built-in current limiting circuit, the current decreases, and a sudden increase of current is avoided. The Table 3 gives a detailed description of graph.

Table 3: Cell Current Based on BMS States

\begin{tabular}{|c|c|c|}
\hline Serial no. & State & $\begin{array}{c}\text { Obtained } \\
\text { Current[A] }\end{array}$ \\
\hline 1 & $\begin{array}{c}\text { Beginning of } \\
\text { Discharge }\end{array}$ & 0 \\
\hline 2 & $\begin{array}{c}\text { End of } \\
\text { Discharge }\end{array}$ & -19.16 \\
\hline 3 & During Standby & 0 \\
\hline 4 & $\begin{array}{c}\text { Beginning of } \\
\text { Charging }\end{array}$ & 30 \\
\hline 5 & Median of Charging & 10.28 \\
\hline 6 & End of Charging & 0 \\
\hline
\end{tabular}

\section{State of Charge (SOC)}

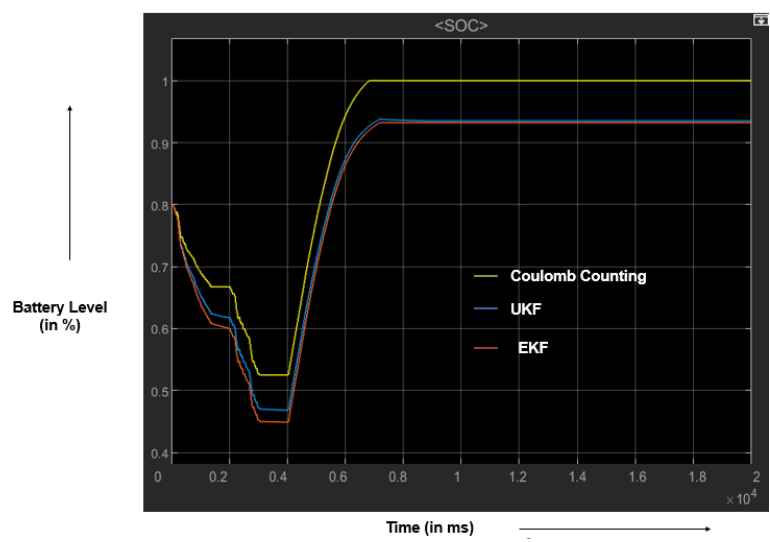

Figure 11. State of Charge

In Fig 11 the graph shows the tracks of three different SoC methods that are used in our work. The yellow colour track indicates the Coulomb Counting method, the Blue one is of the Unscented Kalman filter, and the orange trace indicates the SoC estimation of the Extended Kalman filter. At the beginning of discharging phase, the SoC value of cells is $80 \%$. As the BMS state proceeds to the Standby state then SoC values of cells vary for different methods. It can be concluded that EKF is more accurate and precise in estimation. Table 4 gives a detailed description of the graph. EKF performed better than the UKF by recovering from the initial error.

Table 4: Comparison of Soc Estimation Methods Based On BMS States

\begin{tabular}{|l|l|l|l|l|}
\hline Serial no. & State & $\begin{array}{l}\text { Coulomb } \\
\text { Counting[\%] }\end{array}$ & EKF[\%] & UKF[\%] \\
\hline 1 & $\begin{array}{l}\text { Beginning of } \\
\text { Discharge }\end{array}$ & 80 & 80 & 80 \\
\hline 2 & $\begin{array}{c}\text { End of } \\
\text { Discharge }\end{array}$ & 52.96 & 49.31 & 48.1 \\
\hline 3 & During Standby & 52.45 & 48.7 & 43.6 \\
\hline
\end{tabular}




\begin{tabular}{|l|l|l|l|l|}
\hline 4 & $\begin{array}{l}\text { Beginning of } \\
\text { Charging }\end{array}$ & 60.3 & 56.5 & 55.5 \\
\hline 5 & End of Charging & 100 & 98.62 & 98.46 \\
\hline
\end{tabular}

\section{E. Cell Balancing}

Cell balancing is a very important factor in BMS. Fig 12 depicts the cell balancing function of the BMS. The traces of 6 cells are is shown in the graph.

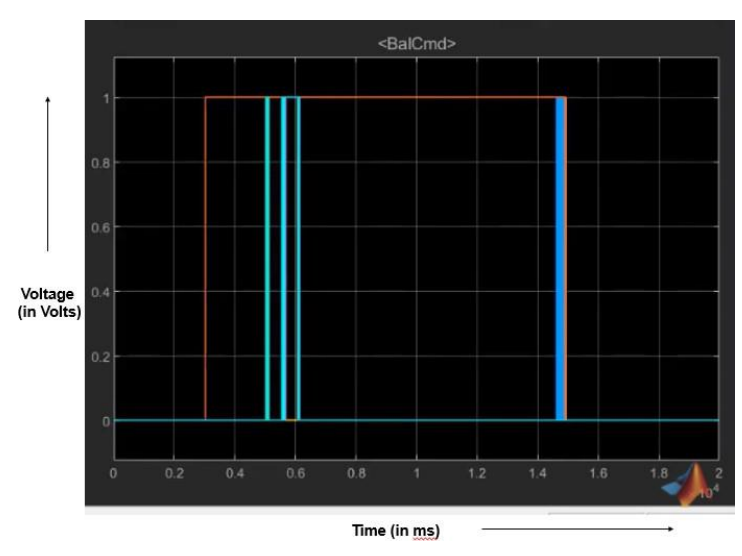

Figure 12. Cell balancing

\section{F. BMS State}

The Complete simulation of BMS is divided into three states as shown in Fig 13, they are

- Discharging

- Standby

- Charging

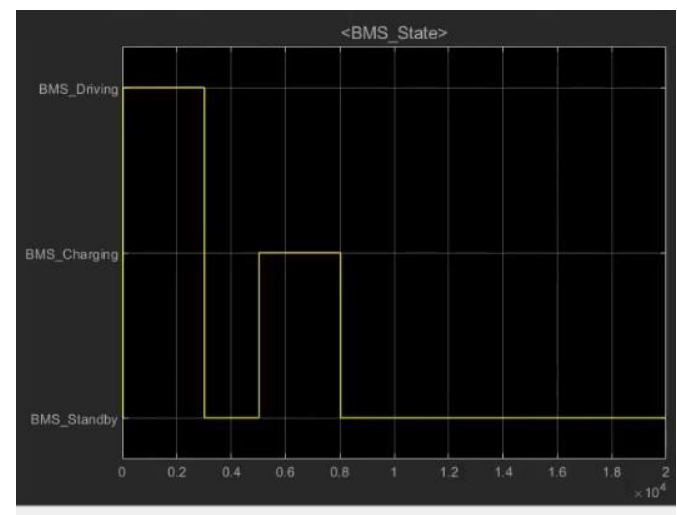

Figure 13. BMS State

All the output graphs are plotted with reference to these states only. First, the BMS goes into discharge state then standby state later and finally goes into Charging state. Almost all the parameters measured are unstable during the discharge state and become zero or low during the standby state and during the charging state the graphs try to attain a stable state with time.

\section{Conclusion}


The BMS Cell voltage, cell temperature, Cell balancing and SoC estimation is performed using MATLAB. Comparison of the three algorithms is done with the help of output graphs simulated in Simulink Scope viewer. From the SoC graph, we can see that the initial SoC value of the battery pack is $75 \%$, but the Estimators were initiated to $80 \%$ to evaluate their potential to recover. At the end of the charging state, the maximum values of SoC of Coulomb counting, EKF, and UKF reached are 100\%, 98.74\%, and $98.46 \%$ respectively. Practically SoC can't reach $100 \%$ but from the values obtained, coulomb counting has reached $100 \%$ due to the accumulation of error from the current sensor as it is an open loop method. Whereas two versions of the Kalman filter are closed-loop and did not reach $100 \%$ by eliminating the error. It can be observed that UKF recovers from the error much earlier than EKF by dropping to a minimum value of $48.7 \%$ and retains it until standby mode is finished. Whereas EKF drops to a minimum value of $47.6 \%$, thereby taking more time to recover from the error. It can be concluded that Extended Kalman Filter estimates more accurately in the discharging phase, while over a substantially extensive range of SoC values, EKF gives a finer SoC estimation.

\section{References}

[1] H. Ren, Y. Zhao, S. Chen, and T. Wang, "Design and implementation of a battery management system with active charge balance based on the soc and soh online estimation," Energy, vol. 166, Oct. 2018. doi: 10.1016/j.energy.2018.10.133.

[2] K. W. E. Cheng, B. P. Divakar, H. Wu, K. Ding, and H. F. Ho, "Battery- management system (bms) and soc development for electrical vehicles," IEEE Transactions on Vehicular Technology, vol. 60, no. 1, pp. 76-88, 2011. doi: 10.1109/TVT.2010. 2089647.

[3] B. Kumar, N. Khare, and P. K. Chaturvedi, "Advanced battery man- agement system using matlab/simulink," in 2015 IEEE International Telecommunications Energy Conference (INTELEC), 2015, pp. 1-6. doi: 10.1109/INTLEC.2015.7572447.

[4] B. Balasingam, M. Ahmed, and K. Pattipati, "Battery management systems - challenges and some solutions," Energies, vol. 13, p. 2825, Jun. 2020. doi: 10.3390/en13112825.

[5] X. Liu, X. Deng, Y. He, X. Zheng, and G. Zeng, "A dynamic state- of-charge estimation method for electric vehicle lithiumion batteries," Energies, vol. 13, p. 121, Dec. 2019. doi: 10.3390/en13010121.

[6] M. Ali, A. Zafar, S. Nengroo, S. Hussain, M. Alvi, and H.-J. Kim, "Towards a smarter battery management system for electric vehicle applications: A critical review of lithium-ion battery state of charge esti- mation,” Energies, vol. 12, p. 446, Jan. 2019. doi: 10.3390/en12030446.

[7] T. Xiao, X. Shi, B. Zhou, and X. Wang, "Comparative study of ekf and ukf for soc estimation of lithium-ion batteries," in 2019 IEEE Innovative Smart Grid Technologies - Asia (ISGT Asia), 2019, pp. 1570-1575. doi: 10 . 1109 / ISGT - Asia . 2019.8880915.

[8] Z. B. Omariba, L. Zhang, and D. Sun, "Review of battery cell balancing methodologies for optimizing battery pack performance in electric vehicles," IEEE Access, vol. 7, pp. 129 335-129 352, 2019. doi: 10.1109/ACCESS.2019.2940090.

[9] M. Khalid, S. S. Sheikh, A. K. Janjua, and H. A. Khalid, "Performance validation of electric vehicle's battery management system under state of charge estimation for lithium-ion battery," in 2018 International Conference on Computing, Electronic and Electrical Engineering (ICE Cube), 2018, pp. 1-5. doi: 10.1109/ICECUBE. 2018.8610969.

[10] M. Daowd, N. Omar, P. Van Den Bossche, and J. Van Mierlo, "Passive and active battery balancing comparison based on matlab simulation," in 2011 IEEE Vehicle Power and Propulsion Conference, 2011, pp. 1-7. doi: 10 . 1109 / VPPC . 2011 6043010.

[11] V. Vaideeswaran, S. Bhuvanesh, and M. Devasena, "Battery management systems for electric vehicles using lithium ion batteries," in 2019 Innovations in Power and Advanced Computing Technologies (i-PACT), vol. 1, 2019, pp. 1-9. doi: 10.1109/ i-PACT44901.2019.8959965.

[12] W. Yan, B. Zhang, G. Zhao, S. Tang, G. Niu, and X. Wang, "A battery management system with a lebesgue-samplingbased extended kalman filter," IEEE Transactions on Industrial Electronics, vol. 66, no. 4, pp. 3227-3236, 2019. doi: 10.1109/TIE. 2018.2842782.

[13] R. Xiong, Y.Zhang, J. Wang, H. He, S. Peng, and M. Pecht, "Lithium- ion battery health prognosis based on a real battery management system used in electric vehicles," IEEE Transactions on Vehicular Technology, vol. 68, no. 5, pp. 4110-4121, 2019. doi: 10.1109/TVT.2018.2864688.

[14] M. Corno and G. Pozzato, "Active adaptive battery aging management for electric vehicles," IEEE Transactions on Vehicular Technology, vol. 69, no. 1, pp. 258-269, 2020. doi: 10.1109/TVT.2019.2940033.

[15] H. Karlsen, T. Dong, Z. Yang, and R. Carvalho, "Temperature- dependence in battery management systems for electric vehicles: Chal- lenges, criteria, and solutions," IEEE Access, vol. 7, pp. 142 203-142 213, 2019. doi: 10 . 1109 / ACCESS . 2019.2943558.

[16] M. Cherukuri and M. Kanthi, "Battery management system design for electric vehicle," in 2019 IEEE International Conference on Distributed Computing, VLSI, Electrical Circuits and Robotics (DISCOVER), 2019, pp. 1-6. doi: 10 . 1109 / DISCOVER47552.2019.9008088.

[17] S. Kivrak, T. Ozer, Y. O 'guz, and E. Erken, "Battery management system imple- "mentation with the passive control method using mosfet as a load," Measurement and Control, vol. 53, p. 002029401988 340, Dec. 2019. doi: $10.1177 / 0020294019883401$.

[18] Y. Xing, E. Ma, K.-L. Tsui, and M. Pecht, "Battery management systems in electric and hybrid vehicles," Energies, vol. 4, Dec. 2011. doi: 10.3390/en4111840. 
[19] h. Hongwen, H. Qin, X. Sun, and Y. Shui, "Comparison study on the battery soc estimation with ekf and ukf algorithms," Energies, vol. 6, pp. 5088-5100, Oct. 2013. doi: 10.3390/en6105088.

[20] P. Salehen, M. Su'ait, H. Razali, and K. Sopian, "Battery management systems (bms) optimization for electric vehicles (evs) in malaysia," vol. 1831, Apr. 2017, p. 020 032. doi: 10.1063/1.4981173. 